HPLC-SPE-NMR hyphenation in natural products research: optimization of analysis of Croton membranaceus extract

Lambert, Maja; Stærk, Dan; Hansen, Steen Honoré; Jaroszewski, Jerzy W.

Published in:

Magnetic Resonance in Chemistry

DOI:

10.1002/mrc.1613

Publication date:

2005

Document version

Publisher's PDF, also known as Version of record

Citation for published version (APA):

Lambert, M., Stærk, D., Hansen, S. H., \& Jaroszewski, J. W. (2005). HPLC-SPE-NMR hyphenation in natural products research: optimization of analysis of Croton membranaceus extract. Magnetic Resonance in Chemistry, 43, 771-775. https://doi.org/10.1002/mrc.1613 


\title{
HPLC-SPE-NMR hyphenation in natural products research: optimization of analysis of Croton membranaceus extract ${ }^{\dagger}$
}

\author{
Maja Lambert, ${ }^{1}$ Dan Stærk, ${ }^{1}$ Steen Honoré Hansen ${ }^{2}$ and Jerzy W. Jaroszewski ${ }^{1 *}$ \\ ${ }^{1}$ Department of Medicinal Chemistry, Danish University of Pharmaceutical Sciences, Universitetsparken 2, DK-2100 Copenhagen, Denmark \\ 2 Department of Analytical Chemistry, Danish University of Pharmaceutical Sciences, Universitetsparken 2, DK-2100 Copenhagen, Denmark
}

Received 4 October 2004; Revised 18 March 2005; Accepted 12 April 2005

\begin{abstract}
The HPLC-SPE-NMR technique was used for the analysis of a root-bark extract of Croton membranaceus. The components of the extract were separated on an analytical-size reversed-phase HPLC column, the chromatographic peaks were trapped on SPE (solid-phase extraction) cartridges after post-column dilution of the eluate with water and the compounds were eluted from the cartridges with acetonitrile- $d_{3}$ into a $30 \mu 1600 \mathrm{MHz}$ NMR probe in a fully automated procedure. The trapping efficiency of scopoletin (1), the major extract constituent, was much higher on a GP (general phase, a polystyrene-type polymer) SPE phase than on a C18 phase. Thus, under the conditions used, up to $100 \mu \mathrm{g}$ of scopoletin per cartridge could be accumulated linearly after repeated trappings. The maximum achievable NMR signal-to-noise ratio using the GP cartridges was at least four times higher than that achievable with the C18 cartridges. It was shown that excessively long $T_{1}$ relaxation times may compromise experiments in which acetonitrile- $d_{3}$ is used as the cartridge eluent. Nevertheless, the sensitivity gain provided by the HPLC-SPE-NMR technique through repeated peak trappings allowed the acquisition of good-quality proton-detected 2D NMR spectra without the need for solvent suppression. Copyright $\subset 2005$ John Wiley \& Sons, Ltd.
\end{abstract}

KEYWORDS: HPLC-SPE-NMR; extract; Croton membranaceus; solid-phase extraction; scopoletin; relaxation; sensitivity

\section{INTRODUCTION}

Natural products are the most consistently successful source of new drugs. ${ }^{1-3}$ However, a traditional search for new pharmacologically active natural products involves often tedious, repeated chromatographic separations prior to determination of the structures of purified constituents. Not infrequently, time and effort are spent on the isolation of already well-known or otherwise trivial chemical entities, slowing progress in the generation of potentially useful structures. It is therefore of great importance to be able to gain information about extract constituents before investment in the preparative isolation process.

Among various spectroscopic methods, only NMR spectroscopy is capable of providing the full information normally needed for rigorous structure determination of a natural product, including determination of its relative stereochemistry and discrimination between positional isomers. In order to exploit the power of NMR, a full repertoire of homonuclear and heteronuclear 2D experiments must be available. Although valuable information about constituents present can be obtained by high-field NMR studies

${ }^{\dagger}$ Presented as part of a special issue on Hyphenated NMR Techniques.

*Correspondence to: Jerzy W. Jaroszewski, Department of Medicinal Chemistry, Danish University of Pharmaceutical Sciences, Universitetsparken 2, DK-2100 Copenhagen, Denmark. E-mail: jj@dfuni.dk of mixtures, ${ }^{4-6}$ spectra of crude extracts are often dominated by large amounts of common constituents such as carbohydrates. Therefore, full assignment of the NMR spectra of natural products, and especially structure determination of minor constituents, will usually require NMR data acquired with pure compounds. For that reason, HPLC-NMR hyphenation is potentially an extremely important technique in natural products research. ${ }^{7-9}$

However, in order to fulfil the promise it holds, HPLC-NMR has to be developed into a robust technology not suffering from its current limitations. Traditionally, HPLC-NMR data are acquired in on-flow mode, stoppedflow mode, time-sliced stopped-flow mode or loop-storage mode. ${ }^{10-12}$ Although the stopped-flow mode circumvents to some extent sensitivity problems inherent to the NMR technique, it creates diffusion-mediated peak broadening on the HPLC column during chromatographic runs. Loop storage alleviates the latter problem, but sensitivity of the NMR data acquisition is still determined by HPLC. Hence it is necessary to acquire NMR spectra at the analyte concentrations delivered in the HPLC band and in the solvent used for HPLC. Deuterated solvents are frequently used in the mobile phases for chromatographic separations, which is feasible only with certain solvents owing to excessive cost. Usually, the HPLC peak elution volumes are larger than the sensitive volume of the NMR flow cell, hence a considerable fraction of material eluted from the HPLC column does not 
contribute to the NMR signal. The use of higher column loadings helps only as far as it results in higher analyte concentrations and not merely in larger elution bands.

So far, the most promising solution to the above problems is the introduction of a solid-phase extraction (SPE) interface between HPLC and NMR, resulting in the novel hyphenated technique HPLC-SPE-NMR. ${ }^{13,14}$ This technique (1) permits solvent change between HPLC and NMR, (2) concentrates the whole HPLC elution volume of the peak in the NMR flow cell and (3) provides further sensitivity gains through repeated SPE steps. In this paper, we present the application of this novel technique to studies of extracts of root bark of Croton membranaceus Müll. Arg. Alcoholic extracts of roots of this plant are used in Ghana for the treatment of prostatic hypertrophy. ${ }^{15,16}$ C. membranaceus was recently shown to contain a novel imide alkaloid named julocrotine, ${ }^{17}$ which is the only literature report on the chemistry of this species.

\section{RESULTS}

Powdered root-bark of $C$. membranaceus was extracted with ethanol at ambient temperature and the extracts were investigated by reversed-phase HPLC on a $150 \times 4.6 \mathrm{~mm}$ i.d. octadecylsilylsilica column using an acetonitrile gradient in water. The chromatogram is shown in Fig. 1. The extract is dominated by one constituent eluted at a retention time $t_{\mathrm{R}}=14.3 \mathrm{~min}$. The identity of this constituent was determined by an HPLC-SPE-NMR experiment, in which $1.1 \mathrm{mg}$ of the crude extract was injected on to the column, trapping the peak at $t_{\mathrm{R}}=14.3 \mathrm{~min}$ once after post-column dilution of the eluate with water in the ratio 4:5. This resulted in a $600 \mathrm{MHz}{ }^{1} \mathrm{H}$ NMR spectrum (Fig. 2) with a signal-to-noise $(\mathrm{S} / \mathrm{N})$ ratio of 287 in the region $\delta 3.0-8.0$ (128 transients). The $\mathrm{S} / \mathrm{N}$ ratio was improved by multiple trappings and good-quality spectra could be obtained even without suppression of residual solvent resonances; with 10 trappings, excellent quality NOESY, ${ }^{18}$ gHSQC $^{19}$ and $\mathrm{gHMBC}^{20}$ spectra were obtained (Fig. 3), allowing the unambiguous identification of the major extract constituent as scopoletin (1). The NOESY spectrum showed correlations between $\mathrm{H}-4$ and $\mathrm{H}-5$ and between $\mathrm{H}-5$ and $\mathrm{OCH}_{3}$, providing distinction from the positional isomer isoscopoletin (2). The assignment was corroborated by HMBC correlations (Fig. 3). The total amount of $\mathbf{1}$ in the plant extract was $0.004 \%$ dry weight as determined from a calibration curve.
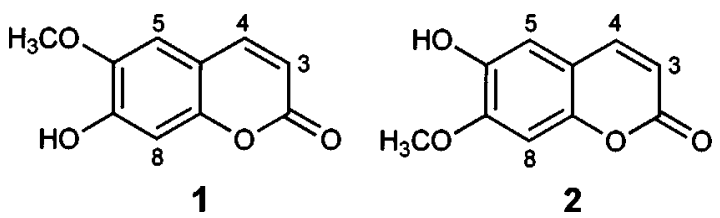

The effectiveness of SPE trapping of scopoletin was investigated on two different SPE stationary phases, Spark HySphere C18 HD phase (octadecylsilylsilica) and HySphere Resin GP phase (reversed-phase sorbent of polystyrene type), measuring the $\mathrm{S} / \mathrm{N}$ ratio in $600 \mathrm{MHz}{ }^{1} \mathrm{H}$ NMR spectra obtained in the HPLC-SPE-NMR mode after repeated injections of solutions of $\mathbf{1}$ (Fig. 4). It appears that the

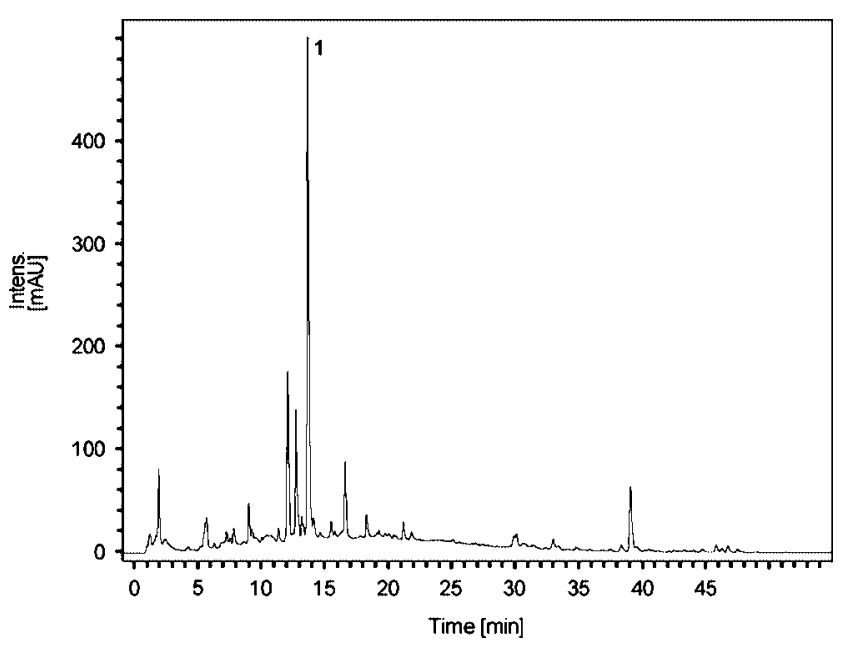

Figure 1. HPLC of crude extract of C. membranaceus (UV absorption trace at $300 \mathrm{~nm}$ ). Conditions: Luna C18(2) column, $150 \times 4.6 \mathrm{~mm}$ i.d., $3 \mu \mathrm{m}$, linear acetonitrile-water gradient from $1: 9$ at $0 \mathrm{~min}$ to $9: 1$ at $55 \mathrm{~min}, 30^{\circ} \mathrm{C}$.

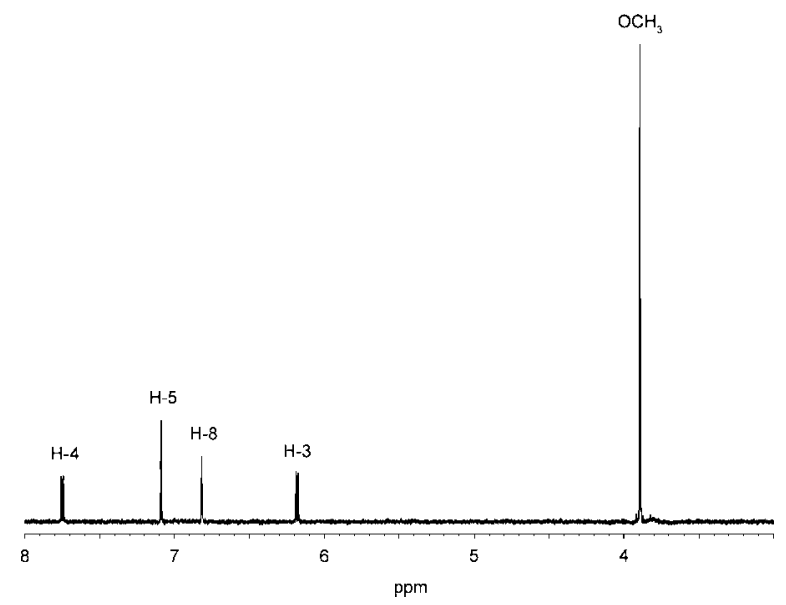

Figure 2. $600 \mathrm{MHz}{ }^{1} \mathrm{H}$ NMR spectrum of 1 after a single trapping on SPE cartridge. The spectrum has an $\mathrm{S} / \mathrm{N}$ ratio of 287 in the region shown (128 transients).

compound accumulates linearly up to about $100 \mu \mathrm{g}$ per cartridge on the GP phase, whereas the accumulation on the C18 HD phase does not progress satisfactorily above $20 \mu \mathrm{g}$ per cartridge under the conditions used.

In order to optimize NMR data accumulation, longitudinal relaxation times of $\mathbf{1}$ were measured in the flow cell after transfer from an SPE cartridge with $\mathrm{CD}_{3} \mathrm{CN}$, and the results were compared with measurements in NMR tubes in $\mathrm{CDCl}_{3}$ and $\mathrm{CD}_{3} \mathrm{CN}$ (Table 1). The $T_{1}$ relaxation times in $\mathrm{CD}_{3} \mathrm{CN}$ were generally much longer than those in $\mathrm{CDCl}_{3}$. The relaxation times measured in the HPLC-SPE-NMR mode were closely similar to those measured with $\mathrm{CD}_{3} \mathrm{CN}$ in NMR tubes in the presence of oxygen (Table 1). The knowledge of relaxation times led to improved efficiency of data accumulation without distortion of the integrals due to selective saturation of the resonances.

SPE trappings of the remaining peaks in the chromatogram (Fig. 1) with $t_{\mathrm{R}}<17$ min failed to produce any ${ }^{1} \mathrm{H}$ NMR spectra. Hence the amount of material represented 

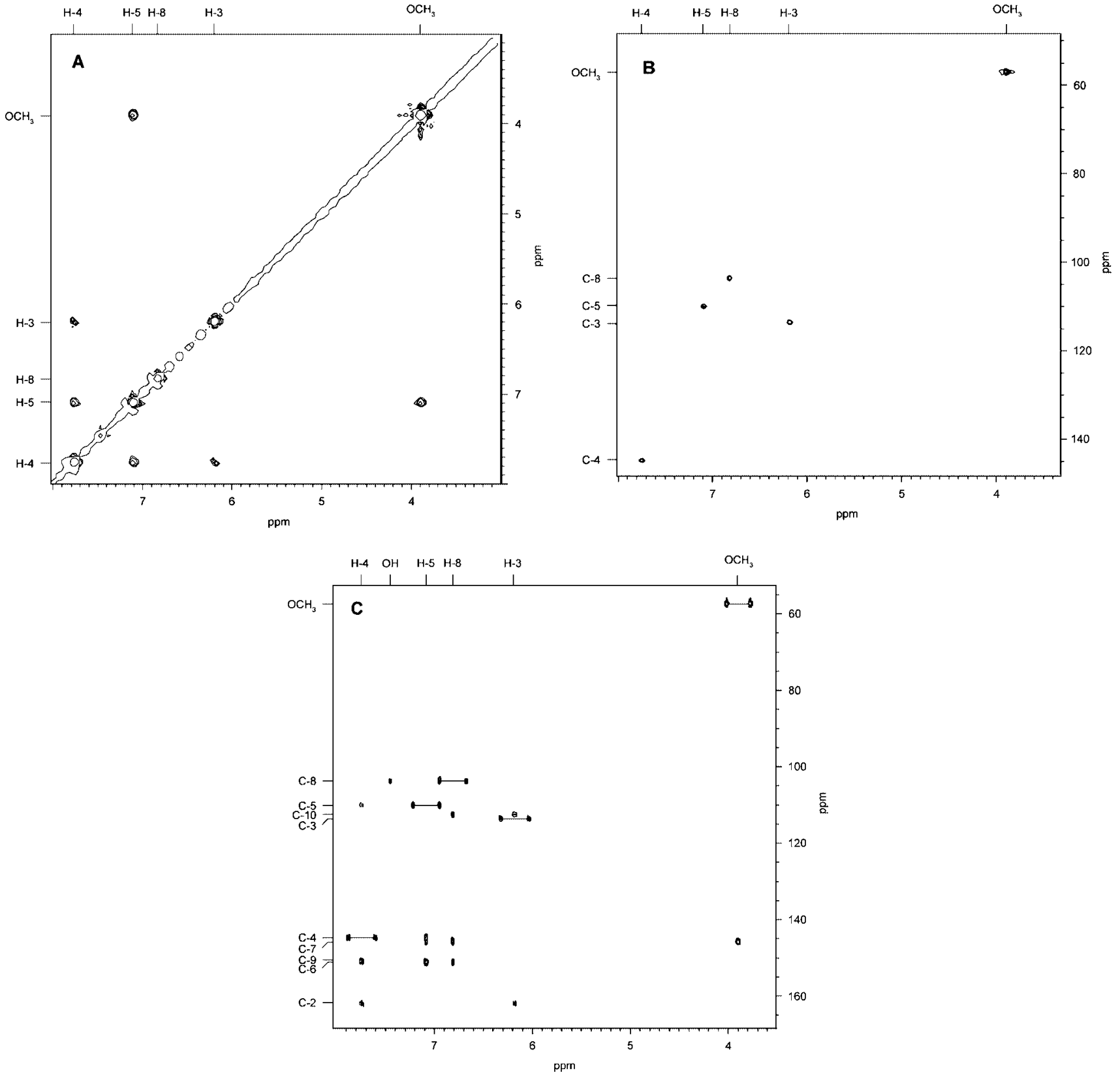

Figure 3. 2D NMR spectra of 1 acquired in a $30 \mu \mathrm{l}$ LC flow probe after trapping 10 times on a GP SPE cartridge. (A) NOESY spectrum showing correlations from $\mathrm{H}-3$ to $\mathrm{H}-4$ to $\mathrm{H}-5$ to $\mathrm{OCH}_{3}$. (B) Gradient-selected HSQC spectrum. (C) Gradient-selected HMBC spectrum. ${ }^{13} \mathrm{C}$ satellites are connected by thin lines.

by these peaks is extremely low. The peaks with $t_{\mathrm{R}}>35 \mathrm{~min}$ gave ${ }^{1} \mathrm{H}$ NMR spectra displaying characteristics of unsaturated fatty acids (terminal methyl triplet at $\delta 0.9$, methylene envelope at $\delta 1.3$ and olefinic hydrogens at $\delta 5-7$ ) and were not further investigated.

\section{DISCUSSION}

Acetonitrile- $d_{3}$ has become a standard solvent for HPLCSPE-NMR experiments owing to its low viscosity and good solubility properties. Moreover, the residual solvent resonances are present in the high-field section of the spectral range, and therefore solvent peak suppression does not affect the most interesting regions of the spectra. However, since acetonitrile only weakly solvates the solute molecules, the correlation times of small molecules are short, resulting in fairly long $T_{1}$ relaxation times (Table 1 ). This decreases the efficiency of data accumulation, in particular with pulse sequences employing $90^{\circ}$ pulse as the read pulse. Hence, the long $T_{1}$ relaxation times observed in acetonitrile have to be taken into account in the experimental setup. Moreover, since the bulk of NMR data for natural products described in the literature is reported in other solvents, typically $\mathrm{CDCl}_{3}$ [or $\mathrm{CD}_{3} \mathrm{OD},\left(\mathrm{CD}_{3}\right)_{2} \mathrm{SO}$ or $\mathrm{D}_{2} \mathrm{O}$ for more polar compounds], use of $\mathrm{CD}_{3} \mathrm{CN}$ makes chemical shift comparisons less efficient.

The present experiments demonstrate that 1 , the polarity of which is representative for many natural products, is effectively trapped in HPLC-SPE-NMR experiments, leading to considerable improvement in the $S / N$ ratio. Hence all standard proton-detected $2 \mathrm{D}$ experiments are readily 


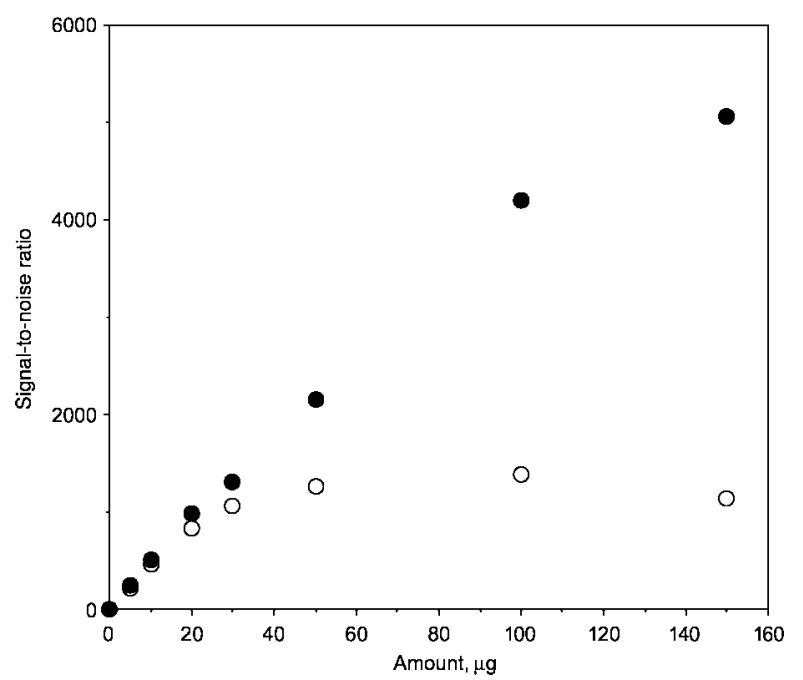

Figure 4. Improvement in $\mathrm{S} / \mathrm{N}$ ratio in the ${ }^{1} \mathrm{H}$ NMR spectrum of 1 after repeated SPE trappings. The GP phase (filled circles) shows a linear improvement in $\mathrm{S} / \mathrm{N}$ ratio up to $\sim 100 \mu \mathrm{g}$ of $1 \mathrm{per}$ cartridge, whereas a decreased trapping efficiency of 1 on the C18 HD phase (open circles) is observed at amounts $>20 \mu \mathrm{g}$ per cartridge.

Table 1. Longitudinal relaxation times of scopoletin (1)

\begin{tabular}{lcccc}
\hline & \multicolumn{4}{c}{ Relaxation time, $T_{1}(\mathrm{~s})$} \\
\cline { 2 - 5 } & $\begin{array}{c}\text { Solution } \\
\text { in }\end{array}$ & $\begin{array}{c}\text { Solution } \\
\text { in } \\
\text { Hydrogen }\end{array}$ & $\begin{array}{c}\text { Solution in } \\
\mathrm{CD}_{3} \mathrm{CN} \text {, argon } \\
\text { purged }^{\mathrm{a}}\end{array}$ & $\begin{array}{c}\text { Solution in } \\
\mathrm{CD}_{3} \mathrm{CN}, \mathrm{SPE} \\
\text { transfer }^{\mathrm{b}}\end{array}$ \\
\hline $\mathrm{C}-3$ & 1.45 & 5.99 & 17.28 & 7.17 \\
$\mathrm{H}-4$ & 1.70 & 4.39 & 8.17 & 5.02 \\
$\mathrm{H}-5$ & 2.02 & 3.93 & 6.43 & 4.39 \\
$\mathrm{H}-8$ & 2.75 & 6.75 & 24.48 & 8.78 \\
$\mathrm{OCH}_{3}$ & 1.73 & 2.47 & 3.52 & 2.23 \\
\hline
\end{tabular}

a Measured at $600 \mathrm{MHz}$ in $5 \mathrm{~mm} \mathrm{NMR} \mathrm{tubes} \mathrm{with} 69 \mathrm{~mm}$ solutions $\left(25^{\circ} \mathrm{C}\right)$.

${ }^{b}$ Measured at $600 \mathrm{MHz}$ in a $30 \mu \mathrm{l}$ flow cell after transfer from SPE cartridge, $5 \mathrm{~mm}$ solution $\left(25^{\circ} \mathrm{C}\right)$.

available, making possible unequivocal determinations of structures of natural products from HPLC-SPE-NMR data and without the use of reference samples. For example, the distinction between $\mathbf{1}$ and $\mathbf{2}$, which have closely similar UV spectra, ESI mass spectra and ${ }^{1} \mathrm{H}$ NMR chemical shifts, is possible only by use of NOESY or HMBC data. This example demonstrates the power of the HPLC-SPE-NMR technique. The fact that multiple trappings can readily achieve large amounts of the analyte is also significant because the suppression of the residual solvent resonances may be unnecessary. This removes problems with distortion of resonances close to the suppressed peaks and gives spectra with correct integrals in the optimal total data acquisition time.

During repeated SPE trappings, the amount of material on the cartridge increases whereas the concentration of the analyte in the peak elution band remains the same. For a particular SPE partition coefficient, this may eventually lead to apparent saturation of the cartridge, after which the additional trappings do not lead to increased accumulation, or even to a loss of the material from the cartridge. The ratio of post-column water dilution and choice of the SPE material may be crucial for the success of the experiment. The ratio of post-column water dilution chosen will always be a compromise between the expected trapping efficiency, a danger of analyte precipitation and backpressure development in the system. The importance of the SPE material is illustrated by a comparison between C18 HD phase and GP phase, shown in Fig. 4. Whereas the latter phase allows a linear improvement in $\mathrm{S} / \mathrm{N}$ ratio after repeated trappings of up to $\sim 100 \mu \mathrm{g}$ of 1 per cartridge, trapping on the C18 HD phase becomes inefficient above $20 \mu \mathrm{g}$ per cartridge (Fig. 4). Hence the maximum $\mathrm{S} / \mathrm{N}$ ratio achieved after repeated trappings on the C18 HD phase was only one-quarter of what could be achieved with the GP phase. Although the actual situation will be different from compound to compound and will be affected by the ratio of post-column dilution with water, the superiority of the GP material in the present case is clearly demonstrated.

In conclusion, the use of the SPE interface in HPLC-NMR experiments provides a sensitivity improvement at least equal to that achievable with cryogenic probes. ${ }^{21}$ Because the sensitivity gain is due to the actual increase of the amount of the analyte relative to the amount of the solvent present, an additional flexibility with respect to experimental setup is provided. A possible disadvantage of the method is potential degradation of the analyte on SPE cartridges; this is minimized by storage of the loaded cartridges in an inert atmosphere (under nitrogen).

\section{EXPERIMENTAL}

\section{Instrumentation}

HPLC separations were performed at $40^{\circ} \mathrm{C}$ on a chromatograph consisting of a Shimadzu SCL-10A system controller, SIL-10AD autoinjector, LC-10AT pump and SPD-M10A diode-array detector using a $150 \times 4.6 \mathrm{~mm}$ i.d., $3 \mu \mathrm{m}$ particle size Luna C18(2) column. The system was controlled with Shimadzu Class-VP version 6.10 software. Separations for the HPLC-SPE-NMR experiments were performed on the same column at $30^{\circ} \mathrm{C}$ using a system consisting of a Bruker LC22 quaternary solvent delivery pump with a Degasys degasser, Agilent 1100 autoinjector and Bruker DAD UV detector. Both HPLC systems operated with a linear gradient of acetonitrile in water from 10 to $90 \%$ in 55 min delivered

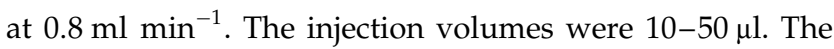
separations were monitored with 254, 270 and $300 \mathrm{~nm} \mathrm{UV}$ absorption traces, the last one being used to deliver start and stop signals for SPE trappings.

A Spark Prospekt II solid-phase extraction device was used for automatic trapping of chromatographic peaks on $2 \times 10 \mathrm{~mm}$ HySphere C18 HD phase (spherically shaped, end-capped octadecylsilylsilica, particle size $7 \mu \mathrm{m}$ ) or GP phase (general phase; spherically shaped polydivinylbenzene polymer, particle size 5-15 $\mu \mathrm{m}$ ) SPE cartridges. Postcolumn make-up water flow in the HPLC-SPE-NMR experiments was delivered by a Knauer K100 Wellchrom pump 


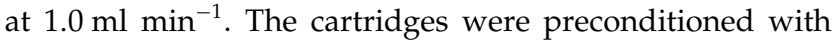

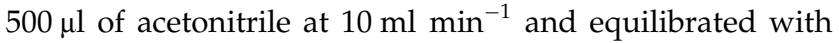

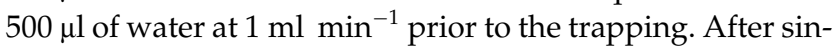
gle or multiple trappings the cartridge was dried for $30 \mathrm{~min}$ at ambient temperature with a stream of nitrogen, and the trapped material was eluted with $\sim 30 \mu$ of acetonitrile- $d_{3}$ (99.8 at.\% of deuterium) and transferred to a $30 \mu \mathrm{l}$ NMR flow probe. The total amount of acetonitrile- $d_{3}$ used for the elution and transfer was $282 \mu \mathrm{l}$ at a transfer rate of $240 \mu \mathrm{l} \mathrm{min}^{-1}$; the analyte transfer conditions were determined experimentally using a reference sample.

NMR data were acquired on a Bruker Avance 600 spectrometer (proton frequency $600.13 \mathrm{MHz}$ ) equipped with either a $30 \mu \mathrm{l}$ inverse ${ }^{1} \mathrm{H}\left\{{ }^{13} \mathrm{C}\right\}$ flow probe or a $5 \mathrm{~mm}$ TXI probe. Chromatography, peak trapping and transfers were controlled with Bruker HyStar version 2.3 software. NMR experiments were controlled and data processing was performed with Bruker XWIN-NMR version 3.1 software.

\section{Plant material}

Roots of Croton membranaceus Müll. Arg. were collected in Ghana, $05^{\circ} 58.357^{\prime} \mathrm{N} 00^{\circ} 10.048^{\prime} \mathrm{W}$, at an altitude of $268 \mathrm{~m}$. A voucher specimen (GC39040) was deposited in Herbarium GC (Ghana Herbarium, Botany Department, University of Ghana, Legon).

\section{Sample preparation}

Dried root-bark of C. membranaceus ( $2 \mathrm{~g}$ ) was extracted overnight with $96 \%$ ethanol $(60 \mathrm{ml})$ at ambient temperature with occasional sonification. The mixture was filtered and the extract evaporated to dryness to yield $43 \mathrm{mg}$ of a residue. Solutions for HPLC and HPLC-SPE-NMR analysis were prepared by making $55 \mathrm{mg} \mathrm{ml}^{-1}$ solutions of crude extracts in 1:1 acetonitrile-water. A $1 \mathrm{mg} \mathrm{ml}^{-1}$ solution of authentic scopoletin (Sigma) was prepared in $1: 1$ acetonitrile-water.

\section{NMR experiments}

1D ${ }^{1} \mathrm{H}$ NMR spectra were obtained either without solvent suppression or with solvent suppression of residual water and acetonitrile signals using a 1D NOESY with double presaturation. In most cases, 128 transients were obtained, collecting $64 \mathrm{~K}$ data points with a sweep width of $20 \mathrm{ppm}$. 2D experiments were performed using standard Bruker library pulse sequences for recording NOESY, ${ }^{18}$ gHSQC $^{19}$ and $\mathrm{gHMBC}^{20}$ experiments. NOESY spectra were acquired with a mixing time of $600 \mathrm{~ms}$, collecting $2 \mathrm{~K} \times 512$ data points, filled to $2 \mathrm{~K} \times 2 \mathrm{~K}$ before Fourier transformation. HSQC and HMBC spectra were optimized for ${ }^{1} J(\mathrm{C}, \mathrm{H})=145 \mathrm{~Hz}$ and ${ }^{n} J(\mathrm{C}, \mathrm{H})=7.7 \mathrm{~Hz}$, collecting $2 \mathrm{~K} \times 256$ data points, filled to $2 \mathrm{~K} \times 1 \mathrm{~K}$ before Fourier transformation. Longitudinal $\left(T_{1}\right)$ relaxation times were determined either in $5 \mathrm{~mm}$ tubes or with a $30 \mu \mathrm{l}$ flow probe following transfer from an SPE cartridge, using the inversion-recovery method with 20 values of variable time delay and fitting the data into a three-parameter equation. All NMR spectra were recorded at $25^{\circ} \mathrm{C}$. The spectra in acetonitrile- $d_{3}$ obtained with the flow probe were referenced to the residual solvent signal set to $\delta\left({ }^{1} \mathrm{H}\right)=1.94$. The spectra recorded in NMR tubes were referenced to internal tetramethylsilane.

\section{REFERENCES}

1. Wrigley SK, Chicarelli-Robinson MI. Annu. Rep. Med. Chem. 1997; 32: 285.

2. Newman DJ, Cragg GM, Snader KM. Nat. Prod. Rep. 2000; 17: 215.

3. Lee K-H. J. Nat. Prod. 2004; 67: 273.

4. Williamson RT, Chapin EL, Carr AW, Gilbert JR, Graupner PR, Lewer P, McKamey P, Carney JR, Gerwick WH. Org. Lett. 2000; 2: 289.

5. Exarchou V, Troganis A, Gerothanassis IP, Tsimidou M, Boskou D. J. Agric. Food Chem. 2001; 49: 2.

6. Choi YH, Tapias EC, Kim HK, Lefeber AW, Erkelens C, Verhoeven JT, Brzin J, Zel J, Verpoorte R. Plant Physiol. 2004; 135: 2398 .

7. Bringmann G, Rückert M, Saeb W, Mudogo V. Magn. Reson. Chem. 1999; 37: 98.

8. Sanvoss M. In On-Line LC-NMR and Related Techniques, Albert K (ed). Wiley: New York, 2002; 111.

9. Wolfender JL, Ndjoko K, Hostettmann K. J. Chromatogr. A 2003; 1000: 437 .

10. Albert K, Dachtler M, Glaser T, Händel H, Lacker T, Schlotterbeck G, Strohschein S, Tseng L-H, Braumann U. J. High Resolut. Chromatogr. 1999; 22: 135.

11. Lindon JC, Nicholson JK, Wilson ID. J. Chromatogr. B 2000; 748 : 233.

12. Braumann U, Spraul M. In On-Line LC-NMR and Related Techniques, Albert K (ed). Wiley: New York, 2002; 23.

13. Nyberg NT, Baumann H, Kenne L. Anal. Chem. 2003; 75: 268.

14. Exarchou V, Godejohann M, Van Beek TA, Gerothanassis IP, Vervoort J. Anal. Chem. 2003; 75: 6288.

15. Abbiw DK. Useful Plants of Ghana. Royal Botanic Gardens: Kew, $1990 ; 148$

16. Mashana NR, Abbiw DK, Addae-Mensah I, Adjanouhoun E, Ahyi MRA, Ekpere JA, Enow-Orock EG, Gbile ZO, Noamesi GK, Odei MA, Odunlami H, Oteng-Yeboah AA, Sarpong K, Sofowora A, Tackie AN. Traditional Medicine and Pharmacopoeia, Contribution to the Revision of Ethnobotanical and Floristic Studies in Ghana. Organization of African Unity: Accra, 2000; 228.

17. Aboagye FA, Sam GH, Massiot G, Lavaud C. Fitoterapia 2000; 71: 461.

18. Jeener J, Meier BH, Bachmann P, Ernst RR. J. Chem. Phys. 1979; 71: 4546.

19. Palmer AG III, Cavanagh J, Wright PE, Rance M. J. Magn. Reson. 1991; 93: 151.

20. Ruiz-Cabello J, Vuister GW, Moonen CTW, van Gelderen P, Cohen JS, van Zijl PCM. J. Magn. Reson. 1992; 100: 282.

21. Spraul M, Freund AS, Nast RE, Withers RS, Maas WE, Corcoran O. Anal. Chem. 2003; 75: 1546. 